\title{
EDITORIAL
}

\section{Pulmonary vascular responses to exercise: a haemodynamic observation}

\author{
R. Saggar***, G.D. Lewis" ${ }^{* * *}$, D.M. Systrom ${ }^{\mp}$, H.C. Champion ${ }^{+}$, R. Naeije $^{\S, \# \#}$ and R. Saggar ${ }^{f, \# \#}$
}

다 xercise testing provides additional information over resting variables and is a standard of care in the assessment of coronary artery disease with less subsequent cardiovascular events. In pulmonary hypertension $(\mathrm{PH})$, right ventricular function is clearly an important determinant of survival. However, right ventricular impairment is currently assessed only during resting conditions. Exercise (stress) testing may provide further insight into the complex paradigm of right ventricular dysfunction, right ventricular-left ventricular interdependence and right ventricular-pulmonary artery coupling. Whether pulmonary artery pressure $(P$ pa $)$-flow relationships during exercise provides a window into earlier diagnosis of functionally significant $\mathrm{PH}$ or adds incrementally to our armamentarium of diagnostic tests and prognostic indicators in $\mathrm{PH}$, is a topic of ongoing investigation. In this issue of the European Respiratory Journal (ERJ), the studies by KovACs et al. [1] and WHYTE et al. [2] discuss the potential clinical utility of identifying "normal" and "abnormal" pulmonary vascular response patterns to exercise in patients aged $\leqslant 50$ yrs.

The clinical significance of a hypertensive $P$ pa response to exercise is currently uncertain. It may reflect a normal variant without clinical significance, or it may reflect a bona fide cardiopulmonary limitation and abnormal phenotype. In support of the latter, asymptomatic relatives of individuals with established idiopathic or familial PH have demonstrated an abnormal response to exercise [3].

Few studies have used right heart catheterisation (RHC) to address whether mean $P$ pa $\left(\bar{P}_{\text {pa }}\right)>30 \mathrm{mmHg}$ during exercise represents an aberrant pulmonary vascular system in "at-risk" populations [4-11]. Recently, ToLLE et al. [9] evaluated a large cohort with exertional dyspnoea who underwent simultaneous cardiopulmonary exercise testing (CPET) and RHC. At maximal exercise, $\bar{P}_{\mathrm{pa}}$ and pulmonary vascular resistance (PVR) were highest, while resting pulmonary arterial hypertension was lowest in normal subjects and intermediate in patients

\footnotetext{
*Heart Lung Institute, St Joseph Hospital and Medical Center, Phoenix, AZ. ${ }^{\#}$ Cardiology Division of the Dept of Medicine and "Pulmonary Division of the Dept of Medicine, Massachusetts General Hospital, Harvard Medical School, Boston, MA. ${ }^{+}$Division of Pulmonary, Allergy, and Critical Care Medicine, University of Pittsburg Medical Center, Pittsburg, PA. fDivision of Pulmonary and Critical Care Medicine, Dept of Medicine, David Geffen School of Medicine at UCLA, Los Angeles, CA, USA. ${ }^{\S}$ Dept of Physiology, Erasme Campus of the Free University of Brussels, Brussels, Belgium. **These authors contributed equally as primary authors. ${ }^{\# \# T h e s e ~ a u t h o r s ~ c o n t r i b u t e d ~ e q u a l l y ~ a s ~ s e n i o r ~}$ authors.
}

CORRESPONDENCE: R. Saggar, Heart Lung Institute, St Joseph Hospital and Medical Center, 500 W. Thomas Rd, Ste 500, Phoenix, AZ 85013, USA. E-mail: rajeev.saggar@chw.edu with exercise-induced $\mathrm{PH}$. These results suggest exerciseinduced PH may be a clinically distinguishable phenotype in the continuum between normal and resting $\mathrm{PH}$.

The 4th World Symposium on PH examined the literature involving healthy volunteers who underwent haemodynamic assessments at rest and during exercise [12]. A systematic review defined a normal resting $\bar{P}_{\text {pa }}$ of $14 \pm 3.3 \mathrm{mmHg}$ with an upper limit of normal of $20.6 \mathrm{mmHg}$ in the supine position. Importantly, age did not affect resting $\bar{P}_{\text {pa. }}$. However, during slight supine exercise $\bar{P}_{\text {pa }}$ was significantly higher in subjects aged $>50$ yrs $(29.4 \pm 8.4 \mathrm{mmHg})$ compared to those aged 30 50 yrs $(20.0 \pm 4.7 \mathrm{mmHg})$ and $<30$ yrs $(18.2 \pm 5.1 \mathrm{mmHg})$. The upper limit of normal for $\bar{P}_{\text {pa }}$ in subjects aged $<50$ yrs was $29.0 \mathrm{mmHg}$ versus $46.2 \mathrm{mmHg}$ in subjects aged $>50$ yrs [12]. Consequently, the exercise component $\left(\bar{P}_{\text {pa }}>30 \mathrm{mmHg}\right)$ of the prior $\mathrm{PH}$ definition was abandoned [12]. This decision was based on the age-dependent nature of exercise $\bar{P}_{\mathrm{pa}}$ [13], limited data on normal subjects and the heterogeneity of the existing data, i.e. type, position and level of exercise [12].

In this issue of the ERJ, Kovacs et al. [1] expand on their prior systematic review and describe the changes in total pulmonary resistance (TPR) and PVR in healthy individuals during primarily supine exercise. This analysis is essential as it importantly accounts for cardiac output (CO) augmentation and the contribution of pulmonary capillary wedge pressure $(P \mathrm{pcw})$, variables complementary to single $\bar{P}$ pa measurements. Importantly, data were stratified by sex, age, type of exercise (i.e. cycle ergometry and treadmill exercise), body position (upright versus supine), and exercise level (slight, submaximal and maximal) as defined by physiological variables including, heart rate, work rate and oxygen uptake. The authors concluded that a moderate decrease in TPR and a mild decrease in PVR (0.95-1.45 dyn.s. $\mathrm{cm}^{-5} \cdot \mathrm{L}^{-1} \cdot \mathrm{min}^{-1}$ ) are seen during the exercise response in healthy normal subjects. The modest increment in transpulmonary gradient (TPG) relative to $\mathrm{CO}$ during exercise that results in a decrease in PVR is probably attributable to passive recruitment and distension of a normally compliant pulmonary circulation with active flow-mediated vasodilation [14, 15].

A limitation of the study by KovACs et al. [1] was the paucity of individuals aged $>50$ yrs. Unlike younger patients, the overall decline in TPR and PVR is only modest in subjects aged 51$69 \mathrm{yrs}$ and $\geqslant 70 \mathrm{yrs}$. Older individuals tend to have greater augmentation in P pcw relative to blood flow during exercise but a lesser decline in TPG [13]. Furthermore, advancing age is associated with an increase in resting PVR secondary to normal age-related increases in $\bar{P}_{\mathrm{pa}}$ and decreases in $\mathrm{CO}$, resulting in a 
doubling of resting PVR over five decades of life [13-18]. In the study by Kovacs et al. [1], subjects aged 51-69 yrs were limited to only 13 and four patients in supine and upright positions, respectively. Of these, calculated PVR was available for only eight $(47 \%)$ subjects. Due to small patient numbers and the multiple variables being studied, we chose to focus only on interpretation of the data set limited to subjects aged $<50 \mathrm{yrs}$ and in the supine position.

An inherent weakness of interpreting PVR changes with exercise is the flow dependency of this variable. The PVR calculation assumes the $\bar{P}_{\text {pa }}-\mathrm{CO}$ relationship is constant and crosses the pressure axis at a value equal to left atrial pressure, where flow is theoretically zero. Accordingly, the acceptance of a single-point PVR for pressure-flow reslationships, as suggested by Kovacs et al. [1], assumes a homogenous response to exercise, irrespective of other factors such as age, relative hypoxia and unrecognised cardiac/respiratory disease, all of which may alter the distensibility of the resistive vessels [19].

Marked differences are seen in pressure-flow relationships in the pulmonary vasculature of healthy normal subjects relative to resting pulmonary arterial hypertension and systolic heart failure-associated PH (table 1). Ideally, assessment of exerciseinduced increases in $\bar{P}_{\text {pa }}$ should be interpreted relative to increases in blood flow (i.e. $\Delta P \mathrm{pa} / \Delta \mathrm{CO}$ ) and specific work rates, rather than relying on a single absolute $P$ pa threshold (i.e. $30 \mathrm{mmHg}$ ) or a peak exercise $\bar{P}$ pa. ReEVEs et al. [33] performed exercise measurements in 63 healthy young adults at rest and at least two levels of exercise and determined average $\Delta \mathrm{Ppa}_{\mathrm{p}}$ $\Delta \mathrm{CO} \approx 1 \mathrm{mmHg} \cdot \mathrm{min} \cdot \mathrm{L}^{-1}$; alternatively, for each $1 \mathrm{~L} \cdot \mathrm{min}^{-1}$ increase in $\mathrm{CO}$, there is an approximate $1 \mathrm{mmHg}$ increase in $\bar{P}_{\text {pa }}$ [33]. This pattern during exercise corresponds well to the cohort of Kovacs et al. [1] which reported $\Delta P_{\mathrm{pa}} / \Delta \mathrm{CO}$ $\approx 1.06 \mathrm{mmHg} \cdot \mathrm{min} \cdot \mathrm{L}^{-1}$ at $\leqslant 50 \mathrm{yrs}$ of age. However, both these studies also showed wide variability in individual responses of $\bar{P}_{\mathrm{pa}}$ and $\Delta P \mathrm{pa} / \Delta \mathrm{CO}$ to exercise. This heterogeneity underscores the importance of defining "normality" specific for age, sex and cardiopulmonary limited populations.

The study by WHYTE et al. [2] examined the haemodynamic response to mild-to-moderate exercise in patients aged $<50$ yrs with normal resting $P$ pa. These authors performed exercise haemodynamic assessments on 38 patients with symptoms of either exertional dyspnoea, abnormal echocardiogram or suspicion of pulmonary thromboembolic disease. Clearly, the patients were not healthy normal controls and presented with potential risk factors for $\mathrm{PH}$, including history of connective tissue disease, anorexigen use or chronic thromboembolic disease. The inclusion of an "at-risk" population was further exemplified as individuals with an exercise $\bar{P}$ pa of $<30 \mathrm{mmHg}$ and an abnormal pressureflow relationship $\left(\Delta P \mathrm{pa} / \Delta \mathrm{CO} \approx 1.63 \pm 0.70 \mathrm{mmHg} \cdot \mathrm{min} \cdot \mathrm{L}^{-1}\right)$ (table 2). During exercise haemodynamic assessment, individuals who increased $\bar{P}_{\text {pa }}>30 \mathrm{mmHg}$ (24 out of 38 ) tended to have a higher

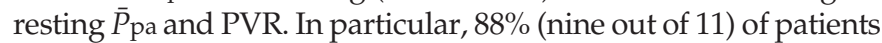
with a resting $\bar{P}_{\text {pa }}$ of $21-24 \mathrm{mmHg}$ developed $\bar{P}_{\text {pa }}>30 \mathrm{mmHg}$ on mild-to-moderate exercise. Despite a heterogeneous population, the baseline demographics between groups were well matched. Importantly, however, the patients who developed $\bar{P}$ pa $>30 \mathrm{mmHg}$ on exercise had a significantly lower diffusing capacity, and trended to have a lower 6-min walk test compared to the remaining 14 patients ( $478 \pm 99$ versus $550 \pm 100 \mathrm{~m} ; \mathrm{p}=0.06$ ).

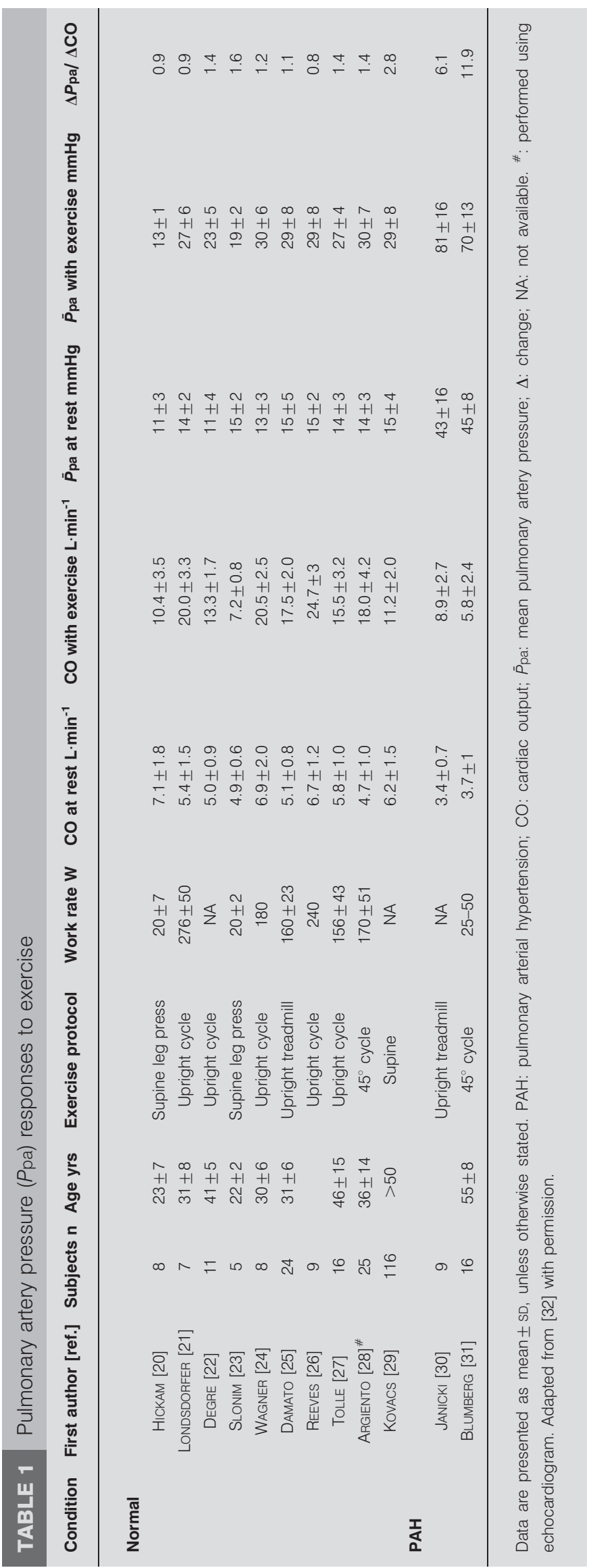




\section{TABLE 2 Pressure-flow responses to exercise with modified exercise definition}

\begin{tabular}{|c|c|c|}
\hline Definitions $^{\#}$ & $\Delta P \mathrm{pa} / \Delta \mathrm{CO}$ & $\Delta \mathrm{TPG} / \Delta \mathrm{CO}$ \\
\hline 1. Exercise $\bar{P}_{\mathrm{pa}}<\mathbf{3 0} \mathrm{mmHg}$ & $1.63 \pm 0.70^{\star}$ & $0.90 \pm 0.74^{+}$ \\
\hline 3. Exercise $\bar{P}_{\mathrm{pa}} \geqslant 30 \mathrm{mmHg}, P_{\mathrm{pcw}} \leqslant 20 \mathrm{mmHg}$, exercise TPG $\geqslant 20 \mathrm{mmHg}$ & $3.61 \pm 1.58$ & $3.07 \pm 1.54$ \\
\hline
\end{tabular}

Several points arose from these conclusions. First, the authors appropriately acknowledge the limitation of the singular focus on $\bar{P}_{\text {pa }}>30 \mathrm{mmHg}$ during exercise. Secondly, the authors did not provide homogenous pressure-flow measurements since the number of data points varied among subjects. Thirdly, exercise was terminated either when subjects reached a workload threshold of $60 \mathrm{~W}$ or when $\bar{P}_{\text {pa }}$ was $>30 \mathrm{mmHg}$. Finally, despite reporting a causal relationship between a higher baseline resting $\bar{P}_{\text {pa }}$ and achieving an exercise $\bar{P}_{\text {pa }}$ of $>30 \mathrm{mmHg}$, our independent analysis revealed that the $\Delta P \mathrm{pa} / \Delta \mathrm{CO}$ of patients with exercise $\bar{P}$ pa $>30 \mathrm{mmHg}$ was significantly higher compared to those with an exercise $\bar{P}_{\text {pa }}<30 \mathrm{mmHg}$ (table 2). This post hoc analysis suggests that while a $\bar{P}_{\text {pa }}$ cut-off of $30 \mathrm{mmHg}$ may distinguish the degree of pulmonary vascular disease, it may not discern a normal from an abnormal exercise response. Alternatively, the $\Delta P \mathrm{pa} / \Delta \mathrm{CO}$ ratio derived from the haemodynamic response to exercise may better delineate both the presence and severity of an underlying pulmonary vasculopathy.

Incorporation of CPET with exercise haemodynamic measurements enables assessment of the functional ramifications of abnormal pulmonary vascular response patterns by providing objective indicators of fitness (i.e. anaerobic threshold, peak oxygen uptake and oxygen uptake kinetics) that are closely related to quality of life and prognosis [34]. CPET also permits delineation of ventilatory efficiency (minute ventilation $/ \mathrm{CO}_{2}$ uptake) and end-tidal carbon dioxide tension patterns have been shown to increase as the $\mathrm{PH}$ burden increases [35]. Simultaneous CPET and exercise haemodynamic assessment is best performed using a cycle ergometer to minimise upper body motion and a continuous ramp protocol to provide a smooth linear increment in work rate. Upright positioning most closely mimics normal physical activity but either upright or supine exercise can be utilised to derive Ppa-flow relationships. Arterial line placement during CPET is not essential but does allow precise systemic blood pressure measurement, as well as serial arterial blood gases, to assess important indicators of pulmonary vascular function, including dead space volume/tidal volume, alveolar-arterial gradient and Fick cardiac outputs when coupled with assessment of oxygen uptake and mixed venous saturations.

Coupling CPET with invasive haemodynamic measurements during exercise in future studies may permit more precise interpretation of haemodynamic measurements and their potential added value in the assessment of patients with suspected pulmonary vascular disease. While the feasibility of concurrent
CPET with pulmonary haemodynamics is unlikely at most centres, the concept of performing both studies within a reasonable time-frame of each other may be a more practical consideration. Ultimately, exercise haemodynamics may ideally allow for an earlier diagnosis of $\mathrm{PH}$ and a more objective and reproducible clinical trial end-point. In fact, to date, small studies with phosphodiestersae-5 inhibitors in World Health Organization Group II PH have suggested that peak oxygen uptake improves proportionately to the degree of reduction in exercise PVR, and that $P$ pa response patterns correlate with peak oxygen uptake, whereas resting measurements do not [36].

The articles by KovAcs et al. [1] and WHYTE et al. [2] provide invaluable insight into the complex methodology required to better understand the pulmonary vascular circuit using exercise haemodynamics. We emphasise that the use of a single haemodynamic variable, such as $\bar{P}_{\text {pa }}$ or PVR, is probably inadequate to define a normal versus abnormal pulmonary vascular response to exercise.

Identifying the role of exercise pulmonary haemodynamics in the evaluation of pulmonary vascular disease and developing a standardised approach for when and how to perform exercise pulmonary haemodynamics, in the context of an evidence-based definition, is clearly needed. The articles by Kovacs et al. [1] and WHYTE et al. [2] are important first steps in this endeavour. Finally, important areas remain open for investigation with regard to exercise and pulmonary vasculature, as follows. 1) Improved validation against invasive gold standards of noninvasive approaches (i.e. CPET or echocardiogram) for the study of pulmonary haemodynamics and right ventricular function. 2) Definition of the limits of age- and sex-related "normal" of averaged slopes of multi-point $\bar{P}_{\text {pa }}-\mathrm{Q}$ relationships at exercise in normoxic and in hypoxic conditions. 3) Characterisation of multipoint pulmonary vascular pressure-flow relationships in PH. 4) Definition of expected increase in pulmonary capillary pressure and TPG with increased $P$ pa at variable levels of exercise, and relationship to gas exchange. 5) Measurements of right ventricular function at exercise.

\section{STATEMENT OF INTEREST}

A statement of interest for R. Naeije and R. Saggar can be found at www.erj.ersjournals.com/site/misc/statements/xhtml

\section{ACKNOWLEDGEMENTS}

We would like to thank R. Vanderpool (Université Libre de Bruxelles, Brussels, Belgium) for providing statistical support. 


\section{REFERENCES}

1 Kovacs G, Olschewski A, Berghold A, et al. Pulmonary vascular resistances during exercise in normal subjects: a systematic review. Eur Respir J 2012; 39: 319-328.

2 Whyte K, Hoette S, Herve P, et al. The association between resting and mild-to-moderate exercise pulmonary artery pressure. Eur Respir J 2012; 39: 313-318.

3 Grunig E, Janssen B, Mereles D, et al. Abnormal pulmonary artery pressure response in asymptomatic carriers of primary pulmonary hypertension gene. Circulation 2000; 102: 1145-1150.

4 Condliffe R, Kiely DG, Peacock AJ, et al. Connective tissue diseaseassociated pulmonary arterial hypertension in the modern treatment era. Am J Respir Crit Care Med 2009; 179: 151-157.

5 Kessler R, Faller M, Weitzenblum E, et al. "Natural history" of pulmonary hypertension in a series of 131 patients with chronic obstructive lung disease. Am J Respir Crit Care Med 2001; 164: 219-224.

6 Kovacs G, Maier R, Aberer E, et al. Borderline pulmonary arterial pressure is associated with decreased exercise capacity in scleroderma. Am J Respir Crit Care Med. 2009; 180: 881-886.

7 Raeside DA, Smith A, Brown A, et al. Pulmonary artery pressure measurement during exercise testing in patients with suspected pulmonary hypertension. Eur Respir J 2000; 16: 282-287.

8 Steen V, Chou M, Shanmugam V, et al. Exercise-induced pulmonary arterial hypertension in patients with systemic sclerosis. Chest 2008; 134: 146-151.

9 Tolle JJ, Waxman AB, Van Horn TL, et al. Exercise-induced pulmonary arterial hypertension. Circulation 2008; 118: 2183-2189.

10 Weitzenblum E, Chaouat A. Severe pulmonary hypertension in COPD: is it a distinct disease? Chest 2005; 127: 1480-1482.

11 Saggar R, Khanna D, Furst DE, et al. Exercise-induced pulmonary hypertension associated with systemic sclerosis: four distinct entities. Arthritis Rheum 2010; 62: 3741-3750.

12 Badesch DB, Champion HC, Sanchez MA, et al. Diagnosis and assessment of pulmonary arterial hypertension. J Am Coll Cardiol 2009; 54: Suppl. 1, S55-S66.

13 Kovacs G, Berghold A, Scheidl S, et al. Pulmonary arterial pressure during rest and exercise in healthy subjects: a systematic review. Eur Respir J 2009; 34: 888-894.

14 Borst HG, McGregor M, Whittenberger JL, et al. Influence of pulmonary arterial and left atrial pressures on pulmonary vascular resistance. Circ Res 1956; 4: 393-399.

15 Hopkins RA, Hammon JW Jr, McHale PA, et al. An analysis of the pulsatile hemodynamic responses of the pulmonary circulation to acute and chronic pulmonary venous hypertension in the awake dog. Circ Res 1980; 47: 902-910.

16 Granath A, Jonsson B, Strandell T. Circulation in healthy old men, studied by right heart catheterization at rest and during exercise in supine and sitting position. Acta Med Scand 1964; 176: 425-446.

17 Granath A, Strandell T. Relationships between cardiac output, stroke volume and intracardiac pressures at rest and during exercise in supine position and some anthropometric data in healthy old men. Acta Med Scand 1964; 176: 447-466.

18 Holmgren A, Jonsson B, Sjostrand T. Circulatory data in normal subjects at rest and during exercise in recumbent position, with special reference to the stroke volume at different work intensities. Acta Physiol Scand 1960; 49: 343-363.

19 Grover RF, Wagner WW, McMurtry IF, et al., eds. Pulmonary Circulation. Handbook of Physiology, The Cardiovascular System,
Peripheral Circulation and Organ Blood Flow. Bethesda, American Physiological Society, 1983; pp. 103-136.

20 Hickam JB, Cargill WH. Effect of exercise on cardiac output and pulmonary arterial pressure in normal persons and in patients with cardiovascular disease and pulmonary emphysema. J Clin Invest 1948; 27: 10-23.

21 Lonsdorfer-Wolf E, Richard R, Doutreleau S, et al. Pulmonary hemodynamics during a strenuous intermittent exercise in healthy subjects. Med Sci Sports Exerc 2003; 35: 1866-1874.

22 Degre S, de Coster A, Messin R, et al. Normal pulmonary pressure-flow relationship during exercise in the sitting position. Int Z Angew Physiol 1972; 31: 53-59.

23 Slonim NB, Ravin A, Balchum OJ, et al. The effect of mild exercise in the supine position on the pulmonary arterial pressure of five normal human subjects. J Clin Invest 1954; 33: 1022-1030.

24 Wagner PD, Gale GE, Moon RE, et al. Pulmonary gas exchange in humans exercising at sea level and simulated altitude. J Appl Physiol 1986; 61: 260-270.

25 Damato AN, Galante JG, Smith WM. Hemodynamic response to treadmill exercise in normal subjects. J Appl Physiol 1966; 21: 959-966.

26 Reeves JT, Groves BM, Sutton JR, et al. Operation Everest II: preservation of cardiac function at extreme altitude. J Appl Physiol 1987; 63: 531-539.

27 Tolle JJ, Waxman AB, Van Horn TL, et al. Exercise-induced pulmonary arterial hypertension. Circulation 2008; 118: 2183-2189.

28 Argiento P, Chesler N, Mule M, et al. Exercise stress echocardiography for the study of the pulmonary circulation. Eur Respir J 2010; 35: 1273-1278.

29 Kovacs G, Berghold A, Scheidl S, et al. Pulmonary arterial pressure during rest and exercise in healthy subjects: a systematic review. Eur Respir J 2009; 34: 888-894.

30 Janicki JS, Weber KT, Likoff MJ, et al. The pressure-flow response of the pulmonary circulation in patients with heart failure and pulmonary vascular disease. Circulation 1985; 72: 1270-1278.

31 Blumberg FC, Riegger GA, Pfeifer M. Hemodynamic effects of aerosolized iloprost in pulmonary hypertension at rest and during exercise. Chest 2002; 121: 1566-1571.

32 Lewis GD. Pulmonary vascular response patterns to exercise: is there a role for pulmonary arterial pressure assessment during exercise in the post-Dana Point era. Adv Pulm Hypertens 2010; 9: 92-100.

33 Reeves JT, Dempsey JA, Grover RF. Pulmonary circulation during exercise. In: Weir EK, Reeves JT, eds. Pulmonary Vascular Physiology and Pathophysiology. 1st Edn. New York, Marcel Dekker, Inc; 1989: 107-135.

34 Arena R, Myers J, Abella J, et al. Development of a ventilatory classification system in patients with heart failure. Circulation 2007; 115: 2410-2417.

35 Lewis GD, Shah RV, Pappagianopolas PP, et al. Determinants of ventilatory efficiency in heart failure: the role of right ventricular performance and pulmonary vascular tone. Circ Heart Fail 2008; 1: 227-233.

36 Lewis GD, Shah R, Shahzad K, et al. Sildenafil improves exercise capacity and quality of life in patients with systolic heart failure and secondary pulmonary hypertension. Circulation 2007; 116: $1555-1562$. 